\title{
Competitive materials based on ilmenite and products of its alteration: composition, structure, properties
}

A. V. Ponariadov', S. Sun², O. B. Kotova, L. Gömze ${ }^{3}$, L. N. Kotov ${ }^{4}$, Y. Wang5, I. Shabalin 5

1Institute of Geology FRC Komi SC UB RAS, Syktyvkar, Russia; alex401@rambler.ru

2Southwest University of Science and Technology, Mianyang, Sichuan, P. R. China

${ }^{3}$ Miskolc University, Miskolc, Hingary

${ }^{4}$ Pitirim Sorokin Syktyvkar State University, Syktyvkar, Russia

5Salford University, Salford, United Kingdom

Titanium is a technologically important material used in power engineering, instrument and machine manufacturing, medicine, cosmetology, ecology, etc. Russia has one of the world's largest explored and variously estimated base of titanium with the possibility of its expansion due to forecast resources. In nature, titanium dioxide is found in three polymorphs - rutile, anatase, and brookite and is extracted mainly from ilmenite ore $\mathrm{CTiO}_{2} \mathrm{con}$ tent of 33.4-66.8\%). However, at the moment, titanium raw materials are a scarce type of mineral raw materials, since deposits of this metal is not being developed in the country.

The creating of own titanium raw material base in the Komi Republic is associated with alluvial Yaregskoye and Pizhemskoye deposits. Ilmenite- leucoxene ores in these deposits are raw materials for the production of both «traditional» titanium dioxide, used, for example, in the paint and varnish industry and in the production of plastics, and the basis for the production of modern functional materials. One-dimensional nanostructured materials based on titanium dioxide are widely used in photocatalysis, as a substrate in the creation of catalysts, implants, reagents that increase blood coagulation, batteries, etc. [1, 2].

We studied the composition, structure, and properties of one-dimensional nanostructured titanium dioxide materials synthesized by the hydrothermal method in the laboratory of mineral raw materials technology of the IG Komi SC UB RAS from a non-magnetic fraction of the gravity concentrate of titanium 
ore of the Pizhemskoe deposit $[3,4]$. The advantage of the method is the possibility of obtaining commercially demanded materials from the gravity concentrate of ilmenite-leucoxene ore without the use of chemical enrichment and refinement of concentrates.

Composition and structure. The synthesized samples are a mixture of two phases: quartz and hydrated sodium titanate $\left(\mathrm{Na}_{\mathrm{x}} \mathrm{H}_{2-\mathrm{x}} \mathrm{Ti}_{3} \mathrm{O}_{7}\right)$. Chemical composition (wt. \%): $\mathrm{TiO}_{2}-74.68, \mathrm{SiO}_{2}-12.64$, $\mathrm{Fe}_{2} \mathrm{O}_{3}-5.44, \mathrm{Al}_{2} \mathrm{O}_{3}-4.71, \mathrm{Na}_{2} \mathrm{O}-0.14, \mathrm{~K}_{2} \mathrm{O}-$ $0.93, \mathrm{MnO}-0.64, \mathrm{CaO}-0.12, \mathrm{MgO}-0.25, \mathrm{P}_{2} \mathrm{O}_{5}-$ $0.09, \mathrm{ZrO}_{2}-0.08, \mathrm{NbO}-0.14$. The increase in the relative content of titanium dioxide is associated with the transition of silicon dioxide into an alkali solution during the synthesis.

The tubular structure of the obtained materials is clearly seen on SEM images: the outer diameter is $70-100 \mathrm{~nm}$, the length is up to $4500 \mathrm{~nm}$. Morphology is affected by the reaction time, the ratio of solid (non-magnetic fraction of gravity ore concentrate) and liquid phase (alkali), and the concentration of $\mathrm{NaOH}$ solution.

Sorption properties. The synthesized $\mathrm{TiO}_{2}$ nanotubes have a developed surface, which is several orders of magnitude higher than the specific surface area of the initial ore, which gives the material high sorption qualities. Studies of the kinetics of the photo-induced decomposition of organic pollutants in aqueous solutions in the presence of titanium dioxide nanotubes have shown that they are not inferior in efficiency to expensive commercial products (in particular, widely used in DegussaP25 photocatalysis) and can become the basis for «clean» technologies to replace the currently used photocatalysts $[2,5]$.

Wave properties. Single and multilayer $\mathrm{TiO}_{2}$ nanotubes can be used as guiding systems (waveguides) of electromagnetic waves (EMW) of the UV range (wavelengths $\lambda=10 \div 380 \mathrm{~nm}$ ) with high flow rates of the transmitted data, compared with the materials used in fiber technology. We studied the effect of the ratio of the EMW length $\lambda$ and the waveguide diameter $d$ on the EMW propagation inside $\mathrm{TiO}_{2}$ nanotubes [6]. It was shown that the observed peak of absorption of UV radiation in the wavelength range $200-380 \mathrm{~nm}$ shifts the maximum wavelengths allowed for waveguides, i.e. it should be less than $200 \mathrm{~nm}$.

The reported study was funded by RFBR and NSFC according to the research project RFBR № 2055-53019 and NSFC № 4191101331, 41672039.

\section{References}

1. Kuo H.-L., Kuo C.-Y., Liu C.-H., Chao J.-H., Lin C.-H. A highly active bi-crystalline photocatalyst consisting of $\mathrm{TiO}_{2}$ (B) nanotube and anatase particle for producing $\mathrm{H}_{2}$ gas from neat ethanol // Catalysis Letters. 2007. V. 113. P. 7-12.

2. Ponaryadov A., Kotova O. Leucoxene and $\mathrm{TiO}_{2}$ photocatalysts for water purification // Materials Science and Engineering. 2013. V. 47. P. 1-6.

3. Ponaryadov A. V., Kotova O. B. Synthesis and properties of nanodisperse structures of titanium minerals by the example of anatase // Doklady Earth Sciences. 2009. V. 425A, No. 3, pp. 467-470.

4. Kotova O. B., Ponaryadov A. V., Gömze L. A. Hydrothermal synthesis of $\mathrm{TiO} 2$ nanotubes from concentrate of titanium ore Pizhemskoe deposit (Russia) // Вестник Института геологии Коми НЦ УрО РАН. 2016. № 1. C. $34-36$.

5. Harja M., Kotova O., Sun S., Ponaryadov A., Shchemelinina T. Efficiency evaluation for titanium dioxide-based advanced materials in water treatment // In: Glagolev S. (Ed.): ICAM 2019, SPEES, pp. 255-258.

6. Kotova O. B., Harja M., Kotov L. N., Ponaryadov A. V. Titanium minerals as prototypes of functional materials with pronounced electromagnetic properties // Vestnik IG Komi SC UB RAS. 2018. № 4. P. 34-39. 